\title{
Randomized Comparison of Cilostazol vs Clopidogrel After Drug-Eluting Stenting in Diabetic Patients CIilostazol for Diabetic Patients in Drug-Eluting Stent (CIDES) Trial
}

\author{
Youngkeun Ahn, MD; Myung Ho Jeong, MD; Jong Weon Jeong, MD; Kye Hun Kim, MD; \\ Tae Hoon Ahn, MD*; Woong Chul Kang, MD*; Chang-Gyu Park, MD**; \\ Jong Hyun Kim, MD ${ }^{\dagger}$; In-Ho Chae, MD ${ }^{\dagger+}$; Chang Wook Nam, MD*; Seung-Ho Hur, MD*; \\ Jang-Ho Bae, MD*; Ki Young Kim, MD\$; Seok Kyu Oh, MD
}

\begin{abstract}
Background Previous studies have shown that cilostazol may not only prevent stent thrombosis, but may also have positive effect in the prevention of restenosis. However, the effect of cilostazol on restenosis after successful deployment of drug-eluting stent (DES) in patients with diabetes mellitus has not been evaluated.

Methods and Results A total of 280 patients at 8 clinical sites were randomized. The patients $(61.7 \pm 9.9$ years old, 163 males) who underwent successful stenting were randomized to aspirin and cilostazol (group I, n=141, $61.2 \pm 9.6$ years old) vs aspirin and clopidogrel (group II, $n=139,62.0 \pm 10.0$ years old) after 1 month of aspirin, cilostazol, and clopidogrel combination treatment. There were no significant differences in baseline characteristics of the groups. The type of DES implanted did not differ between the groups. There were no differences in angiographic and procedural characteristics of the groups. Major adverse cardiac events, including acute and subacute stent thrombosis within 1 month, did not occur in either group. Cases of angiographic late stent thrombosis were $1(0.9 \%)$ in group I and $1(0.8 \%)$ in group II. Follow-up coronary angiography was performed in 237 patients (84.6\%). Mean follow-up duration was 7.1 months. The rate of angiographic restenosis (stent plus 5-mm borders) was $9(8.0 \%)$ in group I and $20(16.1 \%)$ in group II, $\mathrm{p}=0.041)$. The minimal luminal diameter at followup period in group I was $2.55 \pm 0.63 \mathrm{~mm}$ compared with $2.41 \pm 0.83 \mathrm{~mm}$ in group II $(\mathrm{p}=\mathrm{NS})$.

Conclusions Combination therapy with aspirin and cilostazol for the prevention of stent restenosis is comparable or superior to that of aspirin and clopidogrel in diabetic patients who undergo DES implantation. (Circ $J$
\end{abstract} 2008; 72: 35-39)

Key Words: Platelets; Stenosis; Stents

$\mathbf{I}$ n-stent restenosis (ISR) after percutaneous coronary intervention (PCI) has been markedly reduced after the introduction of drug-eluting stents (DES)!,2 Despite this however, in patients with diabetes mellitus (DM), ISR is relatively high? At present, there are questions regarding increased thrombogenicity and long-term outcomes with aspirin and clopidogrel treatment in patients with DES

(Received May 31, 2007; revised manuscript received September 2, 2007; accepted September 21, 2007)

Heart Center, Chonnam National University Hospital, Gwangju, *Gill Heart Center, Gachon Medical School, Incheon, **Department of Cardiology, Korea University Medical College, Seoul, 'Department of Cardiology, Busan Hanseo Hospital, Busan, Cardiovascular Center, Seoul National University Hospital, Seoul, \$Department of Cardiology, Keimyung University Dongsan Medical Center, Daegū, \#Department of Cardiology, Konyang University Hospital, Daejeon and $\$$ Department of Cardiology, Wonkwang University Hospital, Wonkwang, South Korea

This study was presented as featured research at the 2006 Scientific Session of American Heart Association, Chicago, USA.

Mailing address: Myung Ho Jeong, MD, PhD, FACC, FAHA, FESC, FSCAI. Professor, Director of Cardiovascular Research Institute, Heart Center of Chonnam National University Hospital, 8 Hak Dong, Dong Ku, Gwangju 501-757, South Korea. E-mail: myungho@chollian.net All rights are reserved to the Japanese Circulation Society. For permissions, please e-mail: cj@j-circ.or.jp implantation.

Cilostazol is inhibits platelet aggregation by selectively blocking phosphodiesterase type 3, an enzyme that breaks down cyclic adenosine monophosphate (cAMP) 5 In addition, cilostazol also inhibits functions of activated platelets such as the production of thromboxane $\mathrm{B}_{2}$ and the release of platelet-derived growth factor, and exhibits a vasodilator action and a favorable effect on plasma lipid profiles? Previous studies, including the CREST trial, , have shown that cilostazol may not only prevent subacute stent thrombosis, but may also have a positive effect on preventing restenosis. However, the effect of cilostazol on ISR after successful deployment of DES in patients with DM has not been evaluated. Therefore, we performed a prospective randomized study to compare the preventive effect of cilostazol plus aspirin vs clopidogrel plus aspirin treatment on ISR after successful deployment of DES in patients with DM.

\section{Methods}

Study Design

The study was a multicenter, randomized, open clinical trial to test whether cilostazol could prevent ISR after DES implantation in diabetic patients. The study protocol was approved by the institutional review board of each center. 
Table 1 Baseline Patient Characteristics

\begin{tabular}{lccc}
\hline \hline & $\begin{array}{c}\text { Cilostazol group } \\
(n=141)\end{array}$ & $\begin{array}{c}\text { Clopidogrel group } \\
(n=139)\end{array}$ & $p$ value \\
\hline Age (years; mean $\pm S D)$ & $61.2 \pm 9.6$ & $62.0 \pm 10.0$ & 0.973 \\
Male, $n(\%)$ & $87(61.7)$ & $76(54.7)$ & 0.371 \\
Clinical diagnosis, $n(\%)$ & & & 0.157 \\
Acute MI & $37(26.2)$ & $32(23.0)$ & \\
Old MI & $2(1.4)$ & $4(2.9)$ & \\
Unstable angina & $70(49.7)$ & $62(44.6)$ & \\
Stable angina & $32(22.7)$ & $41(29.5)$ & 0.138 \\
Risk factors (medical history), $n(\%)$ & & & 0.784 \\
Current smoking & $56(39.7)$ & $48(34.5)$ & 0.091 \\
Hypertension & $69(48.9)$ & $75(54.0)$ & 0.000 \\
Hyperlipidemia & $27(19.1)$ & $35(25.2)$ & \\
Diabetes & $141(100)$ & $139(100)$ & \\
Treatment of diabetes, $n(\%)$ & $125(88.7)$ & $126(90.6)$ & 0.945 \\
Oral agent & $16(11.3)$ & $13(8.7)$ & $1(0.7)$ \\
Insulin & $0(0)$ & $62.3 \pm 10.2$ & \\
Both & $61.7 \pm 11.1$ & & \\
Left ventricular ejection fraction, \% & & & \\
\hline
\end{tabular}

MI, myocardial infarction.

Table 2 Baseline Angiographic Characteristics

\begin{tabular}{|c|c|c|c|}
\hline & $\begin{array}{l}\text { Cilostazol group } \\
\quad(n=141)\end{array}$ & $\begin{array}{l}\text { Clopidogrel group } \\
(n=139)\end{array}$ & $p$ value \\
\hline New lesions, $n(\%)$ & $138(97.9)$ & $137(98.6)$ & 1.000 \\
\hline Restenosis, $n(\%)$ & $3(2.1)$ & $2(1.4)$ & \\
\hline \multicolumn{4}{|l|}{ Target vessel, $n(\%)$} \\
\hline$L A D$ & $76(53.9)$ & $57(41.0)$ & 0.423 \\
\hline$R C A$ & $35(24.8)$ & $48(34.5)$ & 0.158 \\
\hline$L C X$ & $30(21.3)$ & $34(24.5)$ & 0.799 \\
\hline Left main & $0(0)$ & $2(2.0)$ & 0.243 \\
\hline Type of lesion by AHA/ACC & & & 0.903 \\
\hline$A$ & $1(1.4)$ & $1(1.0)$ & \\
\hline B1 & $11(15.9)$ & $29(29.0)$ & \\
\hline$B 2$ & $23(33.3)$ & $24(24.0)$ & \\
\hline$C$ & $34(49.3)$ & $46(46.0)$ & \\
\hline No. of involved vessels, $n$ & $2.0 \pm 1.8$ & $1.9 \pm 0.8$ & 0.875 \\
\hline 1 & $109(77.3)$ & $101(72.7)$ & \\
\hline 2 & $18(12.8)$ & $26(18.7)$ & \\
\hline 3 & $14(9.9)$ & $12(8.6)$ & \\
\hline Reference-vessel diameter, $\mathrm{mm}$ & $2.95 \pm 0.48$ & $3.00 \pm 0.41$ & 0.229 \\
\hline Pre-PTCA minimal luminal diameter, $\mathrm{mm}$ & $0.70 \pm 0.51$ & $0.60 \pm 0.44$ & 0.217 \\
\hline Pre-PTCA \% diameter stenosis & $78.1 \pm 15.5$ & $79.8 \pm 15.6$ & 0.363 \\
\hline Lesion length, $\mathrm{mm}$ & $23.3 \pm 9.4$ & $24.5 \pm 11.1$ & 0.355 \\
\hline
\end{tabular}

$L A D$, left anterior descending; $R C A$, right coronary artery; $L C X$, left circumflex; PTCA, percutaneous transluminal coronary angioplasty.

A total of 280 patients at 8 centers were randomized. The patients were recruited into the trial prior to the coronary stenting procedure or after stent placement when fully recovered from sedation, at which time they gave informed consent. Prior to stent implantation patients received aspirin at a dose of $100-200 \mathrm{mg} /$ day and a loading dose of clopidogrel of at least $300 \mathrm{mg}$ (up to $600 \mathrm{mg}$ ), as per routine care. After obtaining informed consent and after the procedure, if a stent was placed successfully without in-laboratory complications, aspirin, clopidogrel, and cilostazol were continued for 1 month. From the $2^{\text {nd }}$ month, the patients were randomized to aspirin (100-200 mg/day) and cilostazol $(200 \mathrm{mg} /$ day $)$ vs aspirin $(100-200 \mathrm{mg} /$ day $)$ and clopidogrel $(75 \mathrm{mg} /$ day). Study drugs were continued for 6 months. The patients were also randomized for the type of DES: Cypher vs Taxus stents. All other medications were continued. Cardiac enzymes (ie, creatine kinase (CK), CK-MB, troponin I) were measured at $8-12 \mathrm{~h}$ after the procedure and repeated
$8 \mathrm{~h}$ later if more than twice the upper normal limit (UNL). Myocardial infarction (MI) was diagnosed as a 3-fold elevation of the UNL. Inclusion criteria were: (1) target lesion either de novo or restenosis lesion $>50 \%$ and $<100 \%$ diameter stenosis (DS) by visual estimate, (2) successful, uncomplicated DES placement with $<10 \%$ residual stenosis by visual estimate, with Thrombolysis In Myocardial Infarction III flow, without dissection, (3) stented segment $<40 \mathrm{~mm}$ by visual estimate, (4) age $>18$ years, (5) negative pregnancy test in women of child bearing potential and commitment to use contraception or abstinence for the duration of the study, (6) able to give informed consent, (7) able to return for follow-up angiography at 6 months, and (8) non-insulin dependent DM. Exclusion criteria included: (1) prior PCI within 6 months, (2) thrombocytopenia defined as platelet level $<150,000 / \mathrm{ml}$, (3) known bleeding diathesis, (4) known intolerance to cilostazol, aspirin or clopidogrel, (5) acute MI with CK elevation 3 -fold higher than the UNL within $24 \mathrm{~h}$, 
Table 3 Stent Implantation Procedure Characteristics

\begin{tabular}{lccc}
\hline \hline & $\begin{array}{c}\text { Cilostazol group } \\
(n=141)\end{array}$ & $\begin{array}{c}\text { Clopidogrel group } \\
(n=139)\end{array}$ & $p$ value \\
\hline Type of DES (Cypher/Taxus), $n$ & $(52 / 89)$ & $(64 / 75)$ & 0.344 \\
TIMI 3 flow, $n$ (\%) & $119(84.4)$ & $130(93.5)$ & 0.755 \\
Average no. of stents/lesion, $n$ & $1.3 \pm 0.6$ & $3.4 \pm 0.7$ & 0.361 \\
Average stent size, mm & $3.1 \pm 0.3$ & $25.7 \pm 6.0$ & 0.443 \\
Average stent length, $m$ mm & $25.9 \pm 5.6$ & $14.5 \pm 3.2$ & 1.000 \\
Stent dilatation pressure, atm & $14.2 \pm 3.5$ & $3(3.0)$ & 0.227 \\
GP IIb/III platelet inhibitor use, $n(\%)$ & $2(2.9)$ & 1.000 \\
\hline
\end{tabular}

DES, drug-eluting stent; TIMI, Thrombolysis In Myocardial Infarction; GP, glycoprotein.

Table 4 Quantitative Coronary Angiographic Results

\begin{tabular}{lccc}
\hline \hline & $\begin{array}{c}\text { Cilostazol group } \\
(n=113)\end{array}$ & $\begin{array}{c}\text { Clopidogrel group } \\
(n=124)\end{array}$ & $p$ value \\
\hline Reference diameter, $m m$ & $2.93 \pm 0.49$ & $3.01 \pm 0.42$ & 0.232 \\
MLD, mm & & & 0.216 \\
$\quad$ Baseline & $0.71 \pm 0.50$ & $0.60 \pm 0.44$ & 0.814 \\
Final & $2.78 \pm 0.45$ & $2.78 \pm 0.64$ & 0.421 \\
\% diameter stenosis & & & 0.063 \\
Baseline & $78.1 \pm 15.5$ & $79.8 \pm 15.6$ & 0.358 \\
Final & $12.0 \pm 11.4$ & $9.9 \pm 9.0$ & 0.493 \\
Lesion length, mm & $23.3 \pm 9.4$ & $24.5 \pm 11.1$ & 0.362 \\
F-U MLD, mm & $2.55 \pm 0.63$ & $2.41 \pm 0.83$ & 0.561 \\
F-U\% diameter stenosis & $19.1 \pm 16.9$ & $22.3 \pm 23.9$ & 0.041 \\
Late loss & $0.22 \pm 0.48$ & $0.26 \pm 0.78$ & $20(16.1)$ \\
Restenosis rate (\%) & $9(8.0)$ & & \\
\hline
\end{tabular}

$M L D$, minimal luminal diameter; $F-U$, follow-up.

(6) intraluminal thrombus at target lesion, (7) moderate to severe target lesion calcification, (8) target lesion encompassing side branches $>2 \mathrm{~mm}$ in diameter, (9) heart failure or ejection fraction $<30 \%,(10)$ active peptic ulcer disease or gastrointestinal bleeding, (11) renal insufficiency with creatinine $>2.5 \mathrm{mg} / \mathrm{dl}$, (12) need for warfarin anticoagulation, (13) known hepatic dysfunction, (14) current participation in another randomized trial, (15) inability to return for follow-up angiography, (16) major life-threatening illness, and (17) taking cilostazol within 6 months.

\section{Coronary Angiography and Follow-up}

Patients were followed up clinically at 1,3, and 6 months after stenting and at 6 months they had follow-up angiography. The occurrence of adverse reactions was prospectively monitored. The window for follow-up angiography was 6-9 months. Patients who had early angiography with ISR $(>50 \%$ DS) and/or target lesion revascularization (TLR) prior to the 4-month window was considered to have reached the endpoint and did not undergo additional angiography. Patients with early angiography, but without ISR or TLR, required additional angiography within the window. Images with optimum delineation of the target lesion were selected from among all technically suitable angiograms, and quantitative coronary angiography (QCA) was performed in the core laboratory (Gachon Gill Heart Center) by 2 physicians without any knowledge of the patient's clinical history. The measurements were calibrated using a guide catheter for reference. The reference diameter, minimum luminal diameter (MLD), percent diameter stenosis (\%DS), acute gain, and late loss were determined. The acute gain was calculated from the difference between the MLD values before and after stenting. The late loss was calculated as the difference between MLD after stent implantation and the MLD at follow-up, and the loss index was defined as the late loss/acute gain ratio.

\section{Endpoints}

The primary endpoints were MLD at 6 months of the first lesion stented per patient, as assessed by QCA. The secondary endpoints were mean \%DS per stented segment and binary restenosis, defined as $>50 \%$ DS per stented segment, and major adverse cardiac events.

\section{Statistical Analysis}

Continuous variables are shown as mean \pm standard deviation and categorical variables as proportions. Continuous variables were compared by unpaired t-test or analysis of variance as appropriate. Categorical variables were compared by chi-square. All data was analyzed by intention-to-treat. A $p$ value $<0.05$ was considered to be significant.

\section{Results}

\section{Baseline Patient Characteristics}

A total of 280 patients were randomly assigned to either cilostazol (141: group I) or clopidogrel (139: group II) after successful stent implantation between January 2004 and February 2006. The baseline patient characteristics did not significantly differ between the groups, including age, sex, clinical diagnosis, risk factors etc (Table 1).

Baseline Angiographic Characteristics, Stent Type, and Stent Implantation Procedure Characteristics

There were no significant differences between the groups in the angiographic characteristics (Table2). The lesion types at the stent placement site did not significantly differ, nor was there a significant difference in the type of the stent 
Table 5 Primary Angiographic and Clinical Events in 6-Month Clinical Follow-up

\begin{tabular}{|c|c|c|c|c|c|}
\hline & $\begin{array}{l}\text { Cilostazol group } \\
\quad(n=113)\end{array}$ & $\begin{array}{c}\text { Clopidogrel group } \\
(n=124)\end{array}$ & $\begin{array}{c}\text { Cilostazol group } \\
(n=141)\end{array}$ & $\begin{array}{c}\text { Clopidogrel group } \\
(n=139)\end{array}$ & $p$ value \\
\hline Angiographic events, $n(\%)$ & & & & & 1.000 \\
\hline Acute stent thrombosis & 0 & 0 & & & \\
\hline Subacute stent thrombosis & 0 & 0 & & & \\
\hline Late stent thrombosis & $1(0.9)$ & $1(0.8)$ & & & \\
\hline Clinical events, $n(\%)$ & & & & & 0.079 \\
\hline MI & & & 0 & 0 & \\
\hline Repeat revascularization & & & $7(5.0)$ & $15(10.8)$ & \\
\hline Emergency $C A B G$ & & & 0 & 0 & \\
\hline Death & & & 0 & 0 & \\
\hline
\end{tabular}

Data are the number (\%) of patients.

$C A B G$, coronary artery bypass grafting. Other abbreviation see in Table 1.

implanted or the stent implantation procedure characteristics (Table 3). All patients received unfractionated or lowmolecular-weight heparin.

\section{$Q C A$}

QCA analysis at the time of stent implantation showed no significant differences in reference diameter, MLD before or immediately after procedure, or lesion length (Table 4). Follow-up coronary angiography was performed in 237 patients [113 patients in the cilostazol group (80.1\%); 124 patients in the clopidogrel group (89.2\%)]. Mean follow-up duration was 7.1 \pm 2.4 months. On follow-up QCA, the MLD at the stent implantation site (stent plus 5-mm borders) did not significantly differ between the cilostazol group (2.55 \pm $0.63 \mathrm{~mm})$ and the clopidogrel group $(2.41 \pm 0.83 \mathrm{~mm})(\mathrm{p}=$ NS). Restenosis occurred in 9 patients from the cilostazol group (8.0\%) and 20 patients from the clopidogrel group $(16.1 \%)(\mathrm{p}=0.041)$. There was no significant difference in the late loss of the cilostazol group $(0.22 \pm 0.48 \mathrm{~mm})$ and that of the clopidogrel group $(0.26 \pm 0.78 \mathrm{~mm})(\mathrm{p}=\mathrm{NS})$ (Table 5). Acute and subacute stent thrombosis within 1 month did not occur in either group. Cases of late stent thrombosis were $1(0.9 \%)$ in group I and $1(0.8 \%)$ in group II.

\section{Clinical Evaluation}

All patients were monitored until follow-up angiography, and all deaths, non-fatal cardiovascular events, and other non-fatal adverse events were investigated. There was 1 death in the cilostazol group. Acute MI did not occur in either group. TLR was performed in 7 cases $(5.0 \%)$ in the cilostazol group and in $15(10.8 \%)$ in the clopidogrel group.

Because glycemic control could have influenced the restenosis rate, we analyzed the level of hemoglobin $(\mathrm{Hb}) \mathrm{A}$ lc in both groups. The baseline level of HbAlc in the clopidogrel group was $7.7 \pm 1.3 \%$ and $7.6 \pm 1.5 \%$ in the cilostazol group. At follow-up, the level of HbA1c in the clopidogrel group was $7.8 \pm 2.2 \%$ and $7.8 \pm 2.3 \%$ in the cilostazol group. No significant differences were observed in either group in the initial or follow-up period.

\section{Adverse Reactions}

Significant adverse reactions were not reported in either group.

\section{Discussion}

This randomized, open-labeled trial demonstrated that the effect of combination therapy with aspirin and cilostazol on ISR in high-risk patients with DM who underwent
DES implantation was comparable to that of aspirin and clopidogrel therapy group. There was significantly less binary restenosis in cilostazol-treated patients compared with clopidogrel-treated patients $(8.0 \%$ vs $16.1 \%)$.

The CREST trial ${ }^{6}$ (in which patients received, in addition to aspirin, cilostazol $100 \mathrm{mg}$ b.i.d. or placebo for 6 months; clopidogrel $75 \mathrm{mg}$ daily was administered to all patients for 30 days) demonstrated that treatment with cilostazol resulted in a significantly larger MLD and a significantly lower binary restenosis rate compared with placebo-treated patients after bare-metal stent implantation. The reduction in restenosis observed in this trial was greater than that observed in the pivotal STRESS ${ }^{7}$ and BENESTENT trials?

Before the DES era, recognized predictors of increased restenosis included DM, small vessel diameter, lesion length, and left anterior descending coronary artery site,

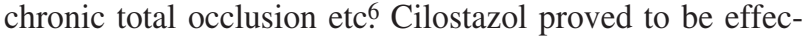
tive in reducing the rate of restenosis in non-diabetics, and its use in oral agent-treated diabetics was associated with a highly significant $63 \%$ reduction in restenosis 6 .

Although DES has reduced the incidence of post-procedural restenosis, adjunct pharmacologic therapy to prevent ISR may be desirable, particularly in patients at high-risk for restenosis, such as those with DM, long lesions, and small vessels.

Patients with DM who have severe endothelial damage often undergo angioplasty. The results of in vivo experiments have shown significant benefits with the use of cilostazol. Aoki et $\mathrm{al}^{9}$ designed a study using a ballooninjury rat model to determine the effects of cilostazol on neointimal formation in diabetic and nondiabetic animals. They found a significant reduction in the ratio of neointimal to medial area, even in the diabetic rats.

The mechanism of cilostazol treatment in the improvement of restenosis can be explained as follows ${ }^{10}$ Cilostazol decreases the activity of phosphodiesterase type 3 , leading to accumulation of cAMP, which initiates a cascade of events including upregulation of the anti-oncogenes p53 and p21 and upregulation of hepatocyte growth factor (HGF). The increase in p53 protein blocks cell cycle progression and induces apoptosis in vascular smooth muscle cells (VSMC), leading to an antiproliferative effect. Upregulation of local HGF stimulates rapid regeneration of endothelial cells, which inhibits neointimal formation via 2 mechanisms: inhibition of abnormal VSMC growth and improvement of endothelial function.

Recent reports have demonstrated that the risk of stent thrombosis is similar between DES and bare-metal stents, ${ }^{11}$ 
but there are 2 important issues regarding DES. In the ACC/AHA/SCAI and ESC guidelines long duration of clopidogrel treatment is recommended, especially in highrisk patients such as those with $\mathrm{DM}^{12,13}$ and a considerable rate of aspirin and clopidogrel resistance is present ${ }^{14}$ Therefore, a different mechanism or stronger antiplatelet agents will be needed in some patients.

In the present study, aspirin, clopidogrel, and cilostazol were continued for 1 month and 1 case of late stent thrombosis occurred in each group. Previous studies demonstrated that cilostazol is as safe and effective as clopidogrel in preventing thrombotic complications after stenting and has an additive effect ${ }^{15,16}$

\section{Study Limitations}

First, aspirin, clopidogrel, and cilostazol were continued for 1 month in both groups before randomization and such a triple antiplatelet regimen could affect the pure outcomes of both groups. Second, even though this was a randomized study, the number of patients and the follow-up rate of coronary angiography was not sufficiently high enough to reach a clear conclusion. Third, intravascular ultrasound study (IVUS) was not used for the precise analysis of the extent of plaque burden and neointimal area at the stent site. At present, we are planning to analyze the stent site in both groups by IVUS.

\section{Conclusion}

The pleotropic effects of cilostazol, in addition to its antithrombotic and vasodilatory attributes, make it a potentially viable treatment option for preventing restenosis following coronary stenting, especially in patients with DM. Our results demonstrated that the effects of combination therapy with aspirin and cilostazol for the prevention of stent thrombosis and restenosis were comparable or superior to those of aspirin and clopidogrel.

\section{Acknowledgments}

This study was supported by Ostuka Clinical Research Grant and Cardiovascular Research Foundation Asia.

\section{References}

1. Morice MC, Serruys PW, Sousa JE, Fajadet J, Ban Hayashi E, Perin M, et al; RAVEL Study Group. Randomized Study with the SirolimusCoated Bx Velocity Balloon-Expandable Stent in the Treatment of Patients with de Novo Native Coronary Artery Lesions: A randomized comparison of a sirolimus-eluting stent with a standard stent for coronary revascularization. $N$ Engl J Med 2002; 346: 1773-1780.

2. Park SJ, Shim WH, Ho DS, Raizner AE, Park SW, Hong MK, et al. A paclitaxel-eluting stent for the prevention of coronary restenosis. $N$
Engl J Med 2003; 348: 1537-1545.

3. Dibra A, Kastrati A, Mehilli J, Pache J, Schuhlen H, von Beckerath $\mathrm{N}$, et al; ISAR-DIABETES Study Investigators. Paclitaxel-eluting or sirolimus-eluting stents to prevent restenosis in diabetic patients. $N$ Engl J Med 2005; 353: 663-670.

4. Gurbel PA, Tantry US. Drug Insight: Clopidogrel nonresponsiveness. Nat Clin Pract Cardiovasc Med 2006; 3: 387-395.

5. Douglas JS. Role of adjunct pharmacologic therapy in the era of drugeluting stents. Atheroscler Suppl 2005; 6: 47-52.

6. Douglas JS Jr, Holmes DR Jr, Kereiakes DJ, Grines CL, Block E, Ghazzal ZM, et al; Cilostazol for Restenosis Trial (CREST) Investigators. Coronary stent restenosis in patients treated with cilostazol. Circulation 2005; 112: 2826-2832.

7. Serruys PW, de Jaegere P, Kiemeneij F, Macaya C, Rutsch W, Heyndrickx G, et al. A comparison of balloon-expandable-stent implantation with balloon angioplasty in patients with coronary artery disease: Benestent Study Group. N Engl J Med 1994; 331: 489-495.

8. Fischman DL, Leon MB, Baim DS, Schatz RA, Savage MP, Penn I, et al. A randomized comparison of coronary-stent placement and balloon angioplasty in the treatment of coronary artery disease: Stent Restenosis Study Investigators. N Engl J Med 1994; 331: 496-501.

9. Aoki M, Morishita R, Hayashi S, Jo N, Matsumoto K, Nakamura T, et al. Inhibition of neointimal formation after balloon injury by cilostazol, accompanied by improvement of endothelial dysfunction and induction of hepatocyte growth factor in rat diabetes model. Diabetologia 2001; 44: 1034-1042.

10. Morishita R. A scientific rationale for the CREST trial results: Evidence for the mechanism of action of cilostazol in restenosis. Atheroscler Suppl 2005; 6: 41-46.

11. Moreno R, Fernandez C, Hernandez R, Alfonso F, Angiolillo DJ, Sabate M, et al. Drug-eluting stent thrombosis: Results from a pooled analysis including 10 randomized studies. J Am Coll Cardiol 2005; 45: $954-959$.

12. Smith SC Jr, Feldman TE, Hirshfeld JW Jr, Jacobs AK, Kern MJ, King SB 3rd, et al; American College of Cardiology/American Heart Association Task Force on Practice Guidelines; American College of Cardiology/American Heart Association/Society for Cardiovascular Angiography and Interventions Writing Committee to Update the 2001 Guidelines for Percutaneous Coronary Intervention. ACC/ AHA/SCAI 2005 Guideline Update for Percutaneous Coronary Intervention--summary article: A report of the American College of Cardiology/American Heart Association Task Force on Practice Guidelines (ACC/AHA/SCAI Writing Committee to Update the 2001 Guidelines for Percutaneous Coronary Intervention). Circulation 2006; 113: $156-175$.

13. Silber S, Albertsson P, Aviles FF, Camici PG, Colombo A, Hamm C, et al; Task Force for Percutaneous Coronary Interventions of the European Society of Cardiology. Guidelines for percutaneous coronary interventions: The Task Force for Percutaneous Coronary Interventions of the European Society of Cardiology. Eur Heart J 2005; 26: 804-847.

14. Lev EI, Patel RT, Maresh KJ, Guthikonda S, Granada J, DeLao T, et al. Aspirin and clopidogrel drug response in patients undergoing percutaneous coronary intervention: The role of dual drug resistance. J Am Coll Cardiol 2006; 47: 27-33.

15. Lee SW, Park SW, Hong MK, Lee CW, Kim YH, Park JH, et al. Comparison of cilostazol and clopidogrel after successful coronary stenting. Am J Cardiol 2005; 95: 859-862.

16. Lee SW, Park SW, Hong MK, Kim YH, Lee BK, Song JM, et al. Triple versus dual antiplatelet therapy after coronary stenting: Impact on stent thrombosis. J Am Coll Cardiol 2005; 46: 1833-1837. 